\title{
ERRATUM TO: COMPUTING ROTATION AND SELF-LINKING NUMBERS IN CONTACT SURGERY DIAGRAM
}

\author{
S. DURST and M. KEGEL \\ Mathematisches Institut, Universität zu Köln, Weyertal 86-90, 50931 Köln, Germany \\ e-mails: sdurst@math.uni-koeln.de, mkegel@math.uni-koeln.de
}

(Received August 31, 2017; accepted September 1, 2017)

Erratum to: Acta Mathematica Hungarica 150 (2) (2016), 524-540.

DOI: $10.1007 / \mathrm{s} 10474-016-0660-8$

There was a minor mistake in the formula for computing the Poincarédual of the Euler class of the contact structure in Theorem 5.1(1).

Since an isomorphism between the two presentations of the first homology group in the proof of Theorem 5.1 is given by $\mu_{i}^{j} \mapsto \mu_{i}$, it follows that

$$
\mathrm{PD}(\mathrm{e}(\xi))=\sum_{i=1}^{k} n_{i} \operatorname{rot}_{i} \mu_{i} \in H_{1}(M),
$$

instead of the original formula, where the $n_{i}$ was missing.

This does not have any implications for other results given in the paper.

The online version of the original article can be found under DOI: $10.1007 / \mathrm{s} 10474-016-0660-8$ 